\title{
DiARY FROM THE FRONT LINES
}

\section{Editor's Note}

Dr. Wolff is a board-certified family physician in private practice in Cornelius, North Carolina. He finished his family practice residency in 1997. He has graciously consented to share stories from the trenches of primary care. While his practice diary is taken from actual patient encounters, the reader should be aware that some medication references may represent off-label uses.

We at the Companion are certain that these vignettes will inform, entertain, challenge, and stimulate our readers in their effort to address behavioral issues in the everyday practice of medicine.

\section{"What's That Smell?"}

\section{Christian G. Wolff, M.D.}

\section{Monday}

I'm always impressed with the sudden response you sometimes see when crossing a therapeutic threshold during titration of a medication. Today, MM, a 13-year-old young man, returned for follow-up after an increase in his dose of long-acting methylphenidate. He responded to his third titration, going from no appreciable response to academic success. Not only are cases like this gratifying, but they sure can make you feel better about your diagnostic skills.

\section{Tuesday}

PY was seen today for sinusitis. What makes this interesting is that 6 months ago, PY came to see me to complain that he had lost his sense of smell. Additionally, PY came asking for his own prescription-he had been treated with various antibiotics and nose sprays, as he had been to various urgent care centers over the last year, but nothing seemed to completely cure his symptoms. Therefore, he had done an Internet search and had read that imipenem was a darned strong antibiotic, so he knew that would cure him. I must have looked at him like he was crazy, because he asked me not to look at him like he was crazy. I was able to convince him to let me get a CT scan of his sinuses to see their condition. Lo and behold, his sinuses looked fine, but a cribriform plate meningioma explained his anosmia. Now, he comes in every 2 months or so with a runny nose asking for another $\mathrm{CT}$ scan to see if the tumor is growing back. One problem fixed just to start another.

\section{Wednesday}

Perceptions are such a funny thing. Today, in the space of an hour, 2 moms brought in their daughters to discuss "weight problems." The girls were 1 year apart in age, but were about the same height and within 3 pounds of each other-both, in my estimation, were of reasonable weight. Of course, mom number one thought her child was too skinny, while mom number two found hers too fat. Imagine the amusement if they sat next to each other in the waiting room and struck up conversation!

\section{Thursday}

TW is in today as a new patient to discuss "mood." The 45 -year-old female manufacturer's sales representative tells me I am the third doctor she has seen in the last 6 months. "I do not want you to tell me I am depressed," she says, "because the last 2 doctors kept giving me different antidepressants and they just made me worse. Just mean and irritable, and it's killing my sales this month, which is especially bad because I want to defend my crown as national sales leader. You've got to help me."

There were no "official" diagnoses she was aware of in her family history, but she had been told that she had the personality of her mother's sister, who was a very charming woman who married 4 times (twice to 
the same man) and who apparently was an outstanding saleswoman. The aunt was a family marvel in that she apparently required only 2 hours of sleep nightly. Thus began our conversation about bipolar disease....

\section{Friday}

$\mathrm{KN}$ is a 24-year-old fellow who has had a bumpy life history. This very bright college student has resumed his studies after a couple of years' hiatus that was notable for a psychiatric hospitalization. He was admitted to a tony northeastern psychiatric facility/spa/retreat after experiencing significant psychoses during mania. I see him for routine medical care while he is at school, as his parents distrust the college's physicians (who, by the way, are excellent). While examining his knee, I engaged him in small talk, whereby he volunteered that he had unilaterally stopped his mood stabilizers. (My head popped up so fast I think I had a contrecoup brain injury.) His reason: he thought he was doing great and didn't think he needed the medicine anymore. Besides, he said, he felt so tired since he was taking his medicine, and, now that he had stopped it, he was beginning to get some of his old pep back. (That might explain his twisted knee while dabbling in snowboarding this weekend.)

After admonishing him to restart his medicines, I remembered he was a voracious reader. I suggested he read Kay Jamison's An Unquiet Mind. I hope that reading about her experiences and insights will help him understand himself a little better.

I then took some naproxen for my headache. 